\title{
Prenatal exposure to aluminum or stress: II. Behavioral and performance effects
}

\author{
BRENDA J. ANDERSON, SUSAN M. NASH, MELISSA RICHARD, DAVID S. DUNGAN, \\ and STEPHEN F. DAVIS \\ Emporia State University, Emporia, Kansas
}

\begin{abstract}
In this second report dealing with the effects of prenatal exposure to aluminum or stress, the results of shock-elicited aggression and learned helplessness testing are presented. When compared to controls, aluminum- and stress-exposed offspring displayed significantly more aggressive responses. However, aluminum-exposed offspring spent significantly less time per aggressive response in contact with the target rod. Moreover, aluminum-exposed animals had significantly longer latencies than did stress-exposed animals during the escape-training phase of the learned helplessness study. These results indicated that the prenatal treatments employed may eventuate in behavioral effects with one of these effects being the disruption of a response inhibition/direction mechanism in the aluminum-exposed animals.
\end{abstract}

In a recent publication (Anderson, Williams, Nash, Dungan, \& Davis, 1985), we demonstrated that such birth-related effects as stillbirths, aborted litters, cannibalism, and lower weights were attributable to prenatal exposure to aluminum or stress. On the other hand, several learning and/or behavior effects also have been produced by aluminum exposure. For example, Crapper and Dalton (1973) administered intracranial injections of aluminum chloride to cats and reported that the animals displayed: (1) performance decrements on delayed matching to sample tasks, and (2) poor retention of one-way avoidance responding. Similarly, Petit, Biederman, and McMullen (1980) injected aluminum tartrate into the brains of rabbits and found that treated animals required significantly more trials to learn and relearn a conditioned avoidance response. On the other hand, Bowdler et al. (1979) employed a wide variety of doses of aluminum chloride and aluminum hydroxide and then tested rat subjects on roto-rod, open-field maze, and conditionedavoidance tasks. Aluminum-treated and control groups did not differ significantly in their retention of the conditionedavoidance task. However, it was reported that higher brain aluminum content covaried significantly with: (1) greater distances covered in the open field, and (2) less time spent on the roto rod. These data suggest that aluminum treatment may be more aptly associated with increased excitability, at least in rats. Even though the literature on the behavioral effects of prenatal stress in rats is somewhat limited, what is available appears to agree with the aluminum/activity data reported by Bowdler et al. (1979). For example, Wehmer, Porter, and Scales (1970) reported significantly more open-field behavior on the part of rats whose grandmothers were exposed to prenatal stress.

The present paper reports the results of additional be-

Requests for reprints should be addressed to Stephen F. Davis, Department of Psychology, Emporia State University, Emporia, KS 66801. havioral tests conducted with rats prenatally exposed to aluminum or stress. ${ }^{1}$

\section{PRENATAL TREATMENTS}

As previously noted (Anderson et al., 1985), 16 spermpositive female Holtsman rats were received on the second day of gestation. Six dams were exposed to a 1:4 mixture of Maalox TC and plain tap water for the remainder of gestation and constituted the aluminum group. An additional six dams were assigned to the stress condition, which involved a 2 -sec exposure to a .5-mA inescapable footshock twice daily for the last 10 days of gestation. The remaining four animals received no prenatal treatment and served as controls. These dams delivered a total of 129 healthy pups that were available for continued behavioral testing. More specifically, there were: (1) three litters $(\mathrm{N}=30)$ of stress-exposed animals, one of which was cross-fostered; (2) five litters of aluminum-exposed animals $(\mathrm{N}=56)$, one of which was cross-fostered; the mothers of four of the non-cross-fostered litters were maintained on the Maalox-water mixture until their pups were weaned at 21 days of age; (3) four litters of control animals $(\mathrm{N}=43)$, two of which were cross-fostered.

For each experiment to be reported, comparisons were made between cross-fostered versus non-cross-fostered pups, and males versus females within each main experimental group. As such comparisons uniformly failed to produce significant effects, only main group effects will be reported in the experiments that follow.

\section{SHOCK-ELICITED AGGRESSION}

As Davis, Neilson, Weaver, Dungan, Sullivan, and Tramill (1984) have shown that prenatal exposure to ethanol resulted in increased levels of shock-elicited aggression, this behavioral task was selected for evaluation. 
The positive results reported by Davis et al. (1983) suggest that the present groups receiving some type of prenatal treatment might also display elevated levels of aggressive responding.

\section{Method}

Subjects. Fifteen aluminum-exposed ( 7 males, 8 females), 10 stressexposed ( 5 males, 5 females), and 12 control ( 6 males, 6 females) offspring served as subjects. All subjects were tested at approximately 90 days of age and were maintained on ad lib food and water during experimental testing.

Apparatus. The shock-elicited aggression apparatus consisted of an opaque plastic restraint tube, shock source (Stoelting Model 26170), target rod (Lafayette, Model 80111, omnidirectional lever), singleimpulse counter (Lafayette, Model 58022), and electronic digital timer (Lafayette, Model 90200). The subject's tail, which extended through a $1.5-\mathrm{cm}$ hole in the closed end of the restraint tube, was taped to a wooden dowel rod to prevent escape during shock application. Two copper wires, permanently attached to the dowel rod, served as electrodes for shock administration.

When attacked, the target rod, which extended across the midportion of the open end of the restraint tube, activated an attached microswitch. Closure of the microswitch activated both the timer and the impulse counter, thus yielding both total time of aggression and number of aggressive responses for each subject.

Procedure. A test session involved placing the designated subject in the restraint tube. Once the tail electrode had been taped in place, the subject was allowed $5 \mathrm{~min}$ to habituate to the apparatus. Habituation was followed by the administration of a $200-\mathrm{msec}, 2-\mathrm{mA}$ tail shock every $15 \mathrm{sec}$ for the ensuing $5 \mathrm{~min}$ (i.e., each subject received a total of 20 shocks during its test session). The order for running subjects was determined randomly.

\section{RESULTS AND DISCUSSION}

The mean number of bites directed toward the target rod, and the mean time per bite shown by the aluminumexposed (Group A), stress-exposed (Group S), and control animals (Group C) are shown in Figures 1 and 2, respectively. Separate ANOVAs yielded significance for the groups factor for both the response $[\mathrm{F}(2,34)=7.72$, $\mathrm{p}<.01]$ and time $[\mathrm{F}(2,34)=6.43, \mathrm{p}<.01]$ measures. Subsequent Newman-Keuls tests indicated that Groups $S$ and $A$ made significantly $(p<.01)$ more aggressive

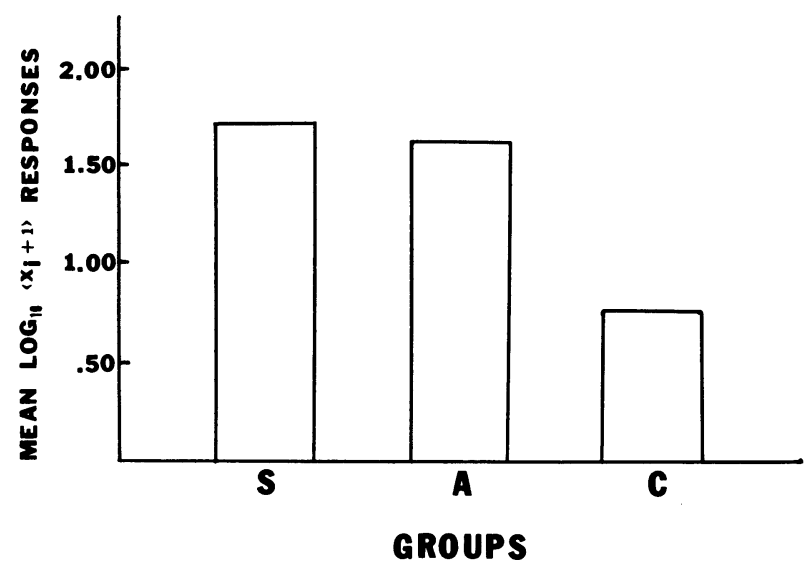

Figure 1. Mean number of aggressive responses shown by Group $S$ (Stress Exposed), Group A (Aluminum Exposed), and Group C (Control).

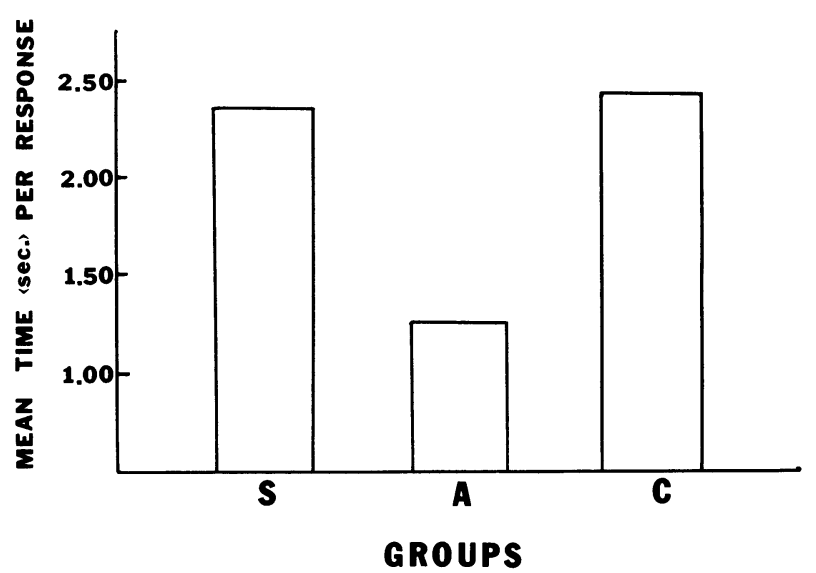

Figure 2. Mean time per aggressive responses for Group S (Stress Exposed), Group A (Aluminum Exposed), and Group C (Control).

responses than did Group $\mathrm{C}$, but that Groups $\mathrm{S}$ and $\mathrm{C}$ spent significantly $(p<.01)$ more time in contact with the target rod per response than did Group A.

In that Group $\mathrm{S}$ and A made significantly more aggressive responses than Group $\mathrm{C}$, it appears that these prenatal treatments were effective in producing the predicted outcome. On the other hand, the significantly lower timeper-response scores shown by Group A suggests that even though these animals may have been more aggressive than control subjects in terms of the sheer number of responses made, they appeared to experience difficulty in directing these responses appropriately.

\section{LEARNED HELPLESSNESS}

As inescapable electric shock was administered to the Group S dams during gestation, the potential for some effect (e.g., facilitation) on the establishment of learned helplessness in their offspring was readily apparent. The shuttle avoidance apparatus was chosen as the test environment. Given the time-of-response behavior displayed by the aluminum-exposed animals in the first study, an evaluation of such directed escape behavior appeared quite relevant.

\section{Method}

Subjects. Eighteen aluminum-exposed (10 males, 8 females), 11 stressexposed ( 5 males, 6 females), and 26 control ( 14 males, 12 females) offspring served as subjects. All subjects were tested at approximately 100 days of age and were maintained on ad lib food and water during experimental testing.

Apparatus. A Lafayette shuttle-avoidance system (Model 85103), which was connected to a Stoelting (Model 26170) shock source, served as the test apparatus. An electronic digital timer(Lafayette, Model 90200) was manually activated when a subject was placed into the apparatus. Breaking a photoelectric beam located $3 \mathrm{~cm}$ beyond the door separating the two compartments stopped the timer.

Procedure. Prior to testing, the control subjects were randomly distributed across two equal-sized groups: CS (Control Shock; 7 males, 6 females), and CNS (Control Nonshock; 7 males, 6 females). Experimental testing encompassed a 6-day period. On Days 1-3 subjects in Groups A (Aluminum-exposed), S (Stress-exposed), and CS (Control Shock) received a daily 90 -sec exposure to a 1-mA inescapable footshock in one chamber of the shuttle-avoidance apparatus. Each subject 
in Group CNS (Control Nonshock) received a 90-sec, nonshock placement in the chamber on Days 1-3. On these days, the door separating the two chambers was closed.

On Days 4-6 all subjects received a daily shock-escape trial. These trials were accomplished by placing the designated subject in the shock compartment of the apparatus. As the door separating the two compartments was raised on these days, the subject could escape to the adjoining (safe) compartment. As soon as the subject's feet touched the grid floor, 1-mA footshock was applied, and the escape timer was activated. Breaking the photobeam in the safe compartment stopped the timer and resulted in termination of the trial. If the safe compartment was not entered within $90 \mathrm{sec}$, the subject was removed from the apparatus and a score of $90 \mathrm{sec}$ was recorded. The order for running subjects was determined randomly each day.

\section{Results and Discussion}

Mean escape latencies for Groups A, S, CS, and CNS for Days 4-6 of testing are shown in Figure 3. As the escape performance of those animals receiving inescapable shock on Days 1-3 (i.e., Groups A, S, and CS) was inferior (i.e., longer latencies) to that shown by the animals not receiving inescapable shock on Days 1-3 (Group CNS), a strong case for the development of learned helplessness can be made. Unweighted means ANOVA showing significance for the Groups $[\mathrm{F}(3,51)$ $=6.74, \mathrm{p}<.01]$ and Days $[\mathrm{F}(2,102)=5.23, \mathrm{p}<.01]$ effects corroborated this graphical impression. NewmanKeuls tests, used to probe these two significant effects, indicated that escape latencies were significantly $(p<.01)$ longer on Day 4 than on Day 5, and significantly ( $p<$ $.01)$ longer on Day 5 than on Day 6. Further, it was found that escape latencies of Group A were significantly $(p<$ .01) longer than those of Group S and CS (which did not differ reliably from each other), and Group CNS. Additionally, it was found that the escape latencies of Groups $S$ and CS were significantly $(\mathrm{p}<.01)$ longer than those of Group CNS.

Taken collectively, these data, as did those of our initial paper (Anderson et al., 1985), indicate that prenatal exposure to aluminum and stress may produce lasting ef-

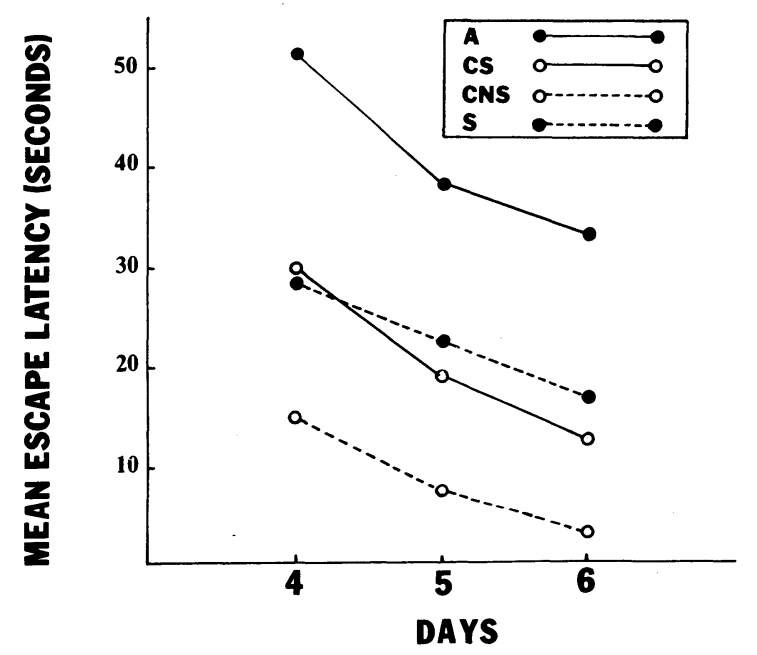

Figure 3. Mean escape latencies (seconds) for Group A (Aluminum Exposed), Group S (Stress Exposed), Group CS (Control Shock), and CNS (Control Nonshock) on Days 4-6 of testing. fects. In that both of the prenatal-exposure groups displayed high levels of aggressive responding, it might be suggested that both prenatal conditions result in response enhancement/facilitation. Such effects are in agreement with the Bowdler et al. (1979) data showing increased excitability in rats following aluminum injection. However, the nondifferential escape performance shown by Groups $\mathrm{CS}$ and $\mathrm{S}$ in the present study of learned helplessness might be interpreted as indicating that such facilitation effects are situation-dependent. With regard to the aluminumexposed offspring, a reasonably strong, and generalizable, case for such prenatal exposure interfering with response inhibition and/or direction appears to be defensible. More specifically aluminum-exposed animals, while displaying high levels of aggressive responding, were not able to sustain contact with the target rod. Further, aluminumexposed animals were obviously unable to successfully direct escape responding in the shuttle-avoidance apparatus. Further research, incorporating both types of prenatal exposure, is needed to better establish these effects and their generalizability.

\section{REFERENCES}

Anderson, B. J., Williams, J. A., Nash, S. M., Dungan, D. S., \& Davis, S. F. (1985). Prenatal exposure to aluminum or stress: I. Birth-related and developmental effects. Bulletin of the Psychonomic Society, 23, 87-89.

Bowdler, N. C., Beasley, D. S., Fritze, E. C., Goulette, A. M., Hatton, J. D., Hession, J., Ostman, D. L., Rugge, D. J., \& Schmittdiel, C. J. (1979). Behavioral effects of aluminum ingestion on animal and human subjects. Pharmacology Biochemistry \& Behavior, 10, 505-512.

Crapper, D. R., \& Dalton, A. J. (1973). Alterations in short-term retention, conditioned avoidance response acquisition and motivation following aluminum induced neurofibrillary degeneration. Physiology \& Behavior, 10, 925-933.

Davis, S. F., Nielson, L. D., Weaver, M. S., Dungan, D. S., Sullivan, P. K., \& Tramill, J. L. (1984). Shock-elicited aggression as a function of early ethanol exposure. The Journal of General Psychology, 110, 93-98.

Petit, T. L., Beiderman, G. B., \& McMullen, P. A. (1980). Neurofibrillary degeneration, dendritic dying back, and learning-memory deficits after aluminum administration: Implications for brain aging. Experimental Neurology, 67, 152-162.

Wehmer, F. Porter, R. H., \& Scales, B. (1970). Prenatal stress influences the behavior of subsequent generations. Communications in Behavioral Biology, 5, 211-214.

\section{NOTES}

1. In addition to the two studies presented in this paper, two additional studies were conducted. The first measured activity of the offspring of aluminum-exposed, stress-exposed, and control dams. the results indicated that the aluminum-exposed offspring were significantly less active than the stress-exposed and control offspring. The significantly lower weights of the aluminum-exposed offspring suggests a possible cause for this effect. The second study investigated differences between these three groups of offspring in the eight-arm radial maze task. The results indicated that both aluminum- and stress-exposed animals took significantly shorter times to enter the initial maze arm and entered significantly more arms on the first day of training. These results might be supportive of a response facilitation/enhancement interpretation, but due to their short (1 day) duration such a claim would be very tenuous.

(Manuscript received for publication June 14, 1985.) 